\title{
A comparative study of long interspersed element-1 protein immunoreactivity in cutaneous malignancies
}

Mohammad Ali Zolfaghari ${ }^{1 \dagger}$, Abbas Karimi ${ }^{1,2^{*}+}$ (D), Elham Kalantari ${ }^{3}$, Alireza Korourian ${ }^{3}$, Alireza Ghanadan ${ }^{4}$, Kambiz Kamyab ${ }^{4}$, Nafiseh Esmaili, ${ }^{2,5}$, Amir Nader Emami Razavi ${ }^{6}$ and Zahra Madjd ${ }^{3 *}$

\begin{abstract}
Background: Skin cancer is the most common cancer worldwide and commonly classified into malignant melanoma (MM) and Nonmelanoma skin cancers (NMSCs), which mainly include basal cell carcinoma (BCC) and squamous cell carcinoma (SCC). The extent to which Long Interspersed Element-1 (LINE-1, L1) ORF1p is expressed in cutaneous malignancies remains to be evaluated. This study aimed to assess LINE-1 ORF1p immunoreactivity in various skin cancer subtypes.

Method: The expression level of LINE-1 ORF1p was evaluated in 95 skin cancer specimens comprising 36 (37.9\%) BCC, 28 (29.5\%) SCC, and 31 (32.6\%) melanoma using the tissue microarray (TMA) technique. Then the association between expression of LINE-1 encoded protein and clinicopathological parameters was analyzed.

Results: We showed that LINE-1 ORF1p expression level was substantially higher in BCC and SCC patients compared with melanoma samples $(p<0.001)$. BCC cases had a higher LINE-1 histochemical score $(\mathrm{H}$-score) compared with SCC cases $(p=0.004)$. In SCC samples, a lower level of LINE-1 ORF1 $p$ expression was associated with age younger than the mean $(p=0.041)$. At the same time, no significant correlation was found between LINE-1 ORF1p expression and other clinicopathological parameters (all $p>0.05$ ).

Conclusions: According to our observation, LINE-1 ORF1p immunoreactivity in various skin tumor subtypes extends previous studies of LINE-1 expression in different cancers. LINE-1ORF1p overexpression in NMSCs compared with MM can be considered with caution as a tumor-specific antigen for NMSCs.
\end{abstract}

Keywords: Skin neoplasms, Retroelements, LINE-1 ORF1p, Immunohistochemistry, Tissue microarray, Biomarker

\footnotetext{
*Correspondence: karimia@tbzmed.ac.ir; Zahra.madjd@yahoo.com;

majdjabari.z@iums.ac.ir

${ }^{\dagger}$ Mohammad Ali Zolfaghari and Abbas Karimi contributed equally to this

work.

'Department of Molecular Medicine, Faculty of Advanced Medical Sciences,

Tabriz University of Medical Sciences, Tabriz, Iran

${ }^{3}$ Oncopathology Research Center, Iran University of Medical Sciences, Tehran,

Iran

Full list of author information is available at the end of the article
}

(c) The Author(s). 2020 Open Access This article is licensed under a Creative Commons Attribution 4.0 International License, which permits use, sharing, adaptation, distribution and reproduction in any medium or format, as long as you give appropriate credit to the original author(s) and the source, provide a link to the Creative Commons licence, and indicate if changes were made. The images or other third party material in this article are included in the article's Creative Commons licence, unless indicated otherwise in a credit line to the material. If material is not included in the article's Creative Commons licence and your intended use is not permitted by statutory regulation or exceeds the permitted use, you will need to obtain permission directly from the copyright holder. To view a copy of this licence, visit http://creativecommons.org/licenses/by/4.0/ The Creative Commons Public Domain Dedication waiver (http://creativecommons.org/publicdomain/zero/1.0/) applies to the data made available in this article, unless otherwise stated in a credit line to the data. 


\section{Background}

Cutaneous malignancy is one of the most common tumors involving millions of humans around the world and, unfortunately, on the rise. Skin cancers are generally classified as malignant melanoma (MM), which represents only $4 \%$ of skin cancer cases and non-melanoma skin cancers (NMSC). NMSC includes two major subtypes of BCC and SCC, amongst others [1,2]. The incidence rate of NMSC is 18-20 times higher than that MM; however, it constitutes a relatively small percentage of skin cancer deaths [3]. BCC and SCC are rarely fatal, whereas $65-74 \%$ of deaths due to cutaneous cancer are caused by malignant melanoma [4]. The high cure rate is associated with BCC and SCC, especially when the lesion is small and diagnosed in early stages $[1,5]$. The early-stage melanoma may be hard to detect but is curable, whereas metastatic form has a poor prognosis and low survival rate [6].

Several risk factors including individual fair skin, blond hair/red hair, freckling, age, gender, personal or family histories, exposure to environmental UVR, high levels of arsenic in drinking water, polycyclic aromatic hydrocarbons, smoking, genetic syndromes and taking immunosuppression are known to induce cutaneous malignancies $[7,8]$. The development of skin cancer takes place in a multistep process by which the accumulation of mutations that can result in genomic instability, which is a prominent feature of most cancers, such as melanoma [9]. One of the mechanisms that are associated with genomic instability is the activation of Transposable Elements (TEs).

TEs are categorized into two subgroups of DNA transposons and RNA transposons or retrotransposons [10]. Retrotransposons can propagate themselves through the human genome using RNA mediators. Long Interspersed Element1 (LINE-1, L1) accounts for about $17 \%$ of the human genome; however, their ability to construct eukaryotic genome structure is a key factor throughout the evolution [11]. Most of these elements are 5 '-truncated and incapable of retrotransposition, but intact and full-length L1 elements are still potent and active sequences in the human genome [12]. A full-length L1 element is $\sim 6 \mathrm{kbp}$ in length and divided into three parts including 1) a $5^{\prime}$ untranslated region (UTR) comprises an internal RNA polymerase II promoter; 2) two open reading frames (ORF1 and ORF2); 3) a 3' UTR which is finished with a variable polyA tail. ORF1 and ORF2 are translated into an RNA-binding protein (40-kDa) that has chaperone activity and a protein with endonuclease and reverse-transcriptase activities $(150-\mathrm{kDa})$, respectively [10]. ORF1p trimers have a prominent role than ORF2p in retrotransposition events such that ORF1p is generated more than the ORF2p $[13,14]$. The function of these elements is intrinsically silenced in their promoters by epigenetic modification and several trans-acting factors $[14,15]$.
In normal somatic cells, methylation is a powerful mechanism of control over the activation of the retrotransposable elements to avoid genomic instability, chromosomal defects, and other genomic rearrangements [16]. Global DNA hypomethylation is a critical feature of human cancers; it may be due to the transcriptional inactivation of LINE-1 elements [17]. LINE-1 promoter hypomethylation has been described in various tumors, including lung cancer, colorectal cancers, breast cancer, prostate cancer, liver cancer, ovarian cancer, and esophageal cancer [14].

In non-small cell lung cancer (NSCLC), transcriptional activation of L1 promoters by hypomethylation results in genomic instability and unfavorable prognosis [18, 19], and in colorectal cancer emerges as an early specific marker [20]. Both invasive and in situ lesions of breast cancer have shown incomplete methylation of LINE-1 promoter resulting in reduced overall survival rate and treatment-resistant in younger patients $[21,22]$. In a recent study, LINE-1 hypomethylation levels have been observed in melanoma tumors thicker $>4 \mathrm{~mm}$ compared with normal melanocyte primary cell cultures [23].

It has revealed that the production of ORF1p due to the LINE-1 expression in in vitro transfected cells is 1000 - to 10,000-fold higher levels compare to ORF2p [24]. More than half of human cancers express LINE-1 ORF1p so that it could be considered as a highly specified tumor marker [17]. Up to now, there is no data regarding the expression of LINE-1 ORF1p in various skin cancer subtypes. Based on previous studies [9, 25, 26], it seems that MM may harbor a higher level of genomic instability and heterogeneity compared with BCC and SCC. This hypothesis raised the question as to whether LINE-1 ORF1p expression differs among various skin neoplasms, and if so, to what extent? In order to achieve immunohistochemically expression data of LINE-1 ORF1p, we aimed to study the LINE-1 ORF1p expression levels by tissue microarray (TMA) in skin cancer specimens comprising $\mathrm{BCC}$, SCC, and melanoma.

\section{Methods}

\section{Characteristics of patients and samples}

A total of 139 formalin-fixed paraffin-embedded (FFPE) specimens from various skin cancer patients were included in the study. These archival tissue samples were obtained from patients with primary skin cancer diagnosed in the Razi and Imam Khomeini Hospitals of Tehran University of Medical Sciences, Tehran, Iran. Data are presented for patients diagnosed with cancer between 2013 2016. Medical records were reviewed to obtain clinicopathological parameters comprising age, gender, lesion type, tumor size, ulceration, metastasis, tumorinfiltrating lymphocytes (TILs), perineural invasion (PNI), 
Clark and Breslow thickness scales (in melanoma), and histological grade (in SCC). Not only the patient's data have no interference in their diagnosis and treatment, but they also were completely kept anonymous. The Research Ethics Committee of Tehran University of Medical Sciences has approved all the study procedures (Ref no: IR.TUMS.REC.1394.1733).

\section{TMA construction}

The entire skin cancer TMA blocks were created as described previously [27-30]. Before TMA construction, all hematoxylin and eosin-stained slides were reviewed by our pathologist colleague (A-K). Then the most morphologically representative areas of tumors in FFPE blocks were annotated. To constructed TMA blocks, 0.6 $\mathrm{mm}$ diameter punches from the region of interests (already annotated) transferred into one empty recipient paraffin block. A TMA block was mad in triplicate 0.6$\mathrm{mm}$ cores of the marked area of each sample using tissue-arraying equipment (MiniCore; ALPHELYS, Plaisir, France). Then $4 \mu \mathrm{m}$ sections were cut from the completed recipient array blocks and transferred to adhesion microscope slides. These glass slides were used for immunohistochemically staining of LINE-1 ORF1p antigenicity.

\section{Immunohistochemistry}

In brief, all the TMA slides were deparaffinized at $60^{\circ} \mathrm{C}$ for $20 \mathrm{~min}$ to be allowed for dehydration with two different alcohol in grade. The solution of hydrogen peroxide $3 \%(\mathrm{v} / \mathrm{v})$ for $20 \mathrm{~min}$ at room temperature was used for blocking endogenous peroxidase. Following washing the slides three times, the antigen retrieval step was performed. This step was followed by autoclaving for 10 min at $121^{\circ} \mathrm{C}$ using $10 \mathrm{mM}$ solution of sodium citrate ( $\mathrm{pH}$ 6.0). Then slides were incubated with the primary monoclonal antibody (1:500 dilution), Anti-LINE 1 ORF1 (EMD Millipore, Cat. No MABC1152, CA, USA) overnight at $4{ }^{\circ} \mathrm{C}$. The slides were then incubated with a secondary antibody cocktail of anti-rabbit/antimouse Envision (Dako, Denmark) for $30 \mathrm{~min}$. Finally, substrate and chromogen (3,3-diaminobenzidine DAB; Dako) was added to the slides and followed by counterstaining with hematoxylin visualize antigen (Dako, Denmark). After dehydration in graded alcohols, slides were cleared in xylene (Dako) and mounted for examination.

As mentioned, colorectal samples are positive for LINE-1 ORF1p expression. We used them as a positive control for confirming the immunolabeling of AntiLINE 1 ORF1. We also used normal skin samples as negative control. Then we optimized and validated antibody titer and dilution on CRC samples as positive control and ten normal skin samples as a negative control. To simultaneously compare the immunoreactivity of the sample, all experiments were run with the same experimental set-up.

\section{Immunostaining assessment}

Immunostaining of LINE-1 ORF1p was independently reviewed by two well-experienced academic pathologists (AK and AG) who were blinded to the patients' outcome and other clinical findings. A consensus outcome was reached in case of discordance. A semi-quantitative scoring approach was used to analyze the staining intensity in slides [30]. First, slides were evaluated at 10× magnification to find positive cores and overall distribution of the tumor cells. Then the percentage of the stained area was examined in high-power fields. The staining intensity was scored as 0 (negative), 1 (weak), 2 (moderate), and 3 (strong). The percentage of positive tumoral cells was scored as $<25 \%, 25-50 \%, 50-75$, and $>75 \%$ of tumor cells. The histochemical score (H-score) was calculated for each case by multiplying the staining intensity and the percentage of positive tumor cells, which yielded a range from 0 to 300 . In this study, the mean $H$-score was chosen to categorize samples as with high or low LINE-1 ORF1p expression.

\section{Statistical analysis}

For comparison of LINE-1 staining scores in various skin cancer subtypes, we did a two-sided Student's t-test to understand the difference between each group means. Moreover, Pearson's chi-square and Pearson's R tests were used to analyzing the significance of association and correlation between LINE-1 ORF1p expression and clinicopathological parameters. $P$ values less than 0.05 were considered statistically significant.

\section{Results}

Following tissue processing and immunohistochemistry staining of skin tumors, samples with missing one or two cores were excluded from the study. A total of 95 samples were included in this study. Of 95 cases, 28 (29.5\%) were SCC, 36 (37.9\%) BCC, and 31 (32.6\%) MM. The present study comprises 67 and 28 male \& female, respectively. There was a male predominance in 3 groups and male to female ratio in SCC, BCC, and MM were as follows: SCC (23 males and five females: 4.6), BCC (26 males and ten females: 2.6) MM (18 males and 13 females: 1.38). The mean age of patients in BCC, SCC, and MM subtypes of skin cancers were calculated as $70.44 \pm 10.2,67.23 \pm 12.6$, and $65.1 \pm 14.2$ years, respectively. Seven (19.4\%), 2 (7.1\%), and 6 (19.4) patients of BCC, SCC and MM subtypes of skin cancer had ulceration in pathological reports. In terms of invasive and in situ forms in SCC, 2 (7.14) patients had in situ, whereas 12 (42.8\%) had invasive form, and for remaining of SCC patients, it was not available. Margin involvement was seen in 1 (2.8\%), 2 (7.1\%), and 7 
(23.3\%) patients of BCC, SCC, and MM patients. Tumorinfiltrating lymphocytes as a prognostic factor and PNI was found in $1(3.6 \%)$ and 1 (3.6\%) patients of SCC and 6 (19.4\%) and 3 (9.7\%) MM patients, respectively. Tumor size was available for $8(28.6 \%)$ SCC cases with a mean value of 4-mm. Metastasis and local recurrence were available for $12(38.7 \%)$ and $17(54.8 \%)$ of MM patients, respectively. Moreover 7 (22.6\%) MM patients had lymphovascular invasion. Melanoma lesions are categorized with Breslow thickness into $\leq 1$ (thin melanoma) and $>1$ $\mathrm{mm}$ (thick melanoma) [31]. Thin melanoma was found in $2(6.5 \%)$ cases and thick melanoma in 8 (25.8\%). In Clark's system, melanomas are divided into two groups: group 1 (Clark levels I and II) and group 2 (Clark levels III through V). Seven (22.6\%) melanoma cases were classified as group 2 , and $6(19.4 \%)$ as group 1 (Table 3), for the remaining it was not available. Tables 1, 2 and 3summarize the clinicopathological features of skin cancer subtypes.

\section{Analysis of LINE-1 ORF1 $p$ expression and its correlation with clinicopathological features}

We first tested LINE-1 ORF1p immunoreactivity on normal skin tissue and colorectal tissues (Fig. 1). Following optimization and validation of antibody titration and dilution on CRC and normal skin tissues as a positive and negative control, we did all controls and patients tests simultaneously. Each tumor type was divided into either lower ( $\leq$ mean of $H$-score) or higher ( $>$ mean of H-score) LINE-1 ORF1p expression. The mean H-score in BCC and SCC samples were 170.4 and 111.84, respectively, whereas the mean $H$-score in melanoma cases was 46.27. Twenty of 36 BCC samples (55.6\%) expressed lower levels of LINE-1 ORF1p, while 16 (44.4\%) cases expressed higher levels (Fig. 2). Low expression of LINE-1 ORF1p was seen in 19 (67.9\%) of 28 SCC cases, while high expression was found in 9 (32.1\%) samples (Fig. 2). Of the 31 melanoma samples, 22 (71\%) had a low expression, and 9 (29\%) showed a high expression of LINE-1 ORF1p (Fig. 2). We found a highly significant difference between mean H-score of LINE-1 ORF1p expression among the three tumor subtypes (all $p<0.01$ ). Box plot diagram of LINE-1 ORF1p expression has been shown in (Fig. 3). Furthermore, the output of the Mann-Whitney $U$ test revealed a significant difference in LINE-1 ORF1p expression between BCC and SCC $(p=0.004)$ and melanomas $(p<0.0001)$. Also, there was a significant difference between the expression of LINE-1 ORF1p in SCC and melanoma $(p=0.002)$. Whereas, we could not find a significant correlation between studied clinicopathological parameters and LINE1 ORF1p expression in BCC and melanoma samples (all $p>0.05$ ) (Tables $1 \& 3$ ). A trend was evident between LINE-1 ORF1p expression and ulceration $(p=0.07)$. In SCC samples, a lower level of LINE-1 ORF1p expression was associated with age lower than the mean $(p=0.041)$, while no significant correlation was found between LINE-1 ORF1p expression and other clinicopathological parameters (all $p>0.05$ ) (Table 2). Regarding the different subtypes of lesions, we did not see any difference in LINE-1 ORF1p immunolabeling of superficial versus

Table 1 Association of expression LINE-1 ORF1p expression with clinicopathological parameters in BCC

\begin{tabular}{|c|c|c|c|c|c|}
\hline \multirow[t]{2}{*}{ Clinicopathological characteristics } & & \multirow{2}{*}{$\begin{array}{l}\text { Total } \\
\text { Number } \\
\text { (\%) }\end{array}$} & \multicolumn{2}{|c|}{ ORF1p expression (mean $\boldsymbol{H}$-score $=170.4$ ) } & \multirow[t]{2}{*}{$\boldsymbol{P}$ value } \\
\hline & & & High (> 170.4) & Low $(<170.4)$ & \\
\hline \multirow[t]{2}{*}{ Mean age \pm SD ( $70.44 \pm 10.2$ years) } & $>70$ & $19(52.8)$ & $7(36.8)$ & $12(63.2)$ & 0.33 \\
\hline & $\leq 70$ & $17(47.2)$ & $9(52.9)$ & $8(47.1)$ & \\
\hline \multirow[t]{2}{*}{ Gender } & Male & $26(72.2)$ & $10(38.5)$ & $16(61.5)$ & 0.24 \\
\hline & Female & $10(27.8)$ & $6(60)$ & $4(40)$ & \\
\hline \multirow[t]{2}{*}{ Ulceration } & Yes & $7(19.4)$ & $2(28.6)$ & $5(71.4)$ & 0.34 \\
\hline & No & 29 (80.6) & $14(48.3)$ & $15(51.7)$ & \\
\hline \multirow[t]{8}{*}{ Histological subtypes } & Nodular & $19(52.8)$ & $10(52.6)$ & $9(47.4)$ & 0.19 \\
\hline & Pigmented & $5(13.9)$ & $2(40)$ & $3(60)$ & \\
\hline & Infilterative & $4(11.1)$ & 0 & $4(100)$ & \\
\hline & Adenoid & $2(5.6)$ & $2(100)$ & 0 & \\
\hline & Micronodular & $2(5.6)$ & $1(50)$ & $1(50)$ & \\
\hline & Metatypical & $2(5.6)$ & 0 & $2(100)$ & \\
\hline & Sclerosing & $1(2.8)$ & 0 & $1(100)$ & \\
\hline & Superficial & $1(2.8)$ & $1(100)$ & 0 & \\
\hline \multirow[t]{2}{*}{ Margin involvement } & Yes & $1(2.8)$ & 0 & $1(100)$ & 0.36 \\
\hline & No & $35(97.2)$ & $16(45.7)$ & $19(54.3)$ & \\
\hline
\end{tabular}


Table 2 Association of LINE-1 ORF1p expression with clinicopathological parameters in SCC

\begin{tabular}{|c|c|c|c|c|c|}
\hline \multirow[t]{2}{*}{ Clinicopathological characteristics } & & \multirow{2}{*}{$\begin{array}{l}\text { Total } \\
\text { Number } \\
(\%)\end{array}$} & \multicolumn{2}{|c|}{ ORF1P expression (mean $\boldsymbol{H}$-score $=111.84$ ) } & \multirow{2}{*}{$\begin{array}{l}\boldsymbol{P} \\
\text { value }\end{array}$} \\
\hline & & & High & Low & \\
\hline \multirow[t]{2}{*}{ Mean age + SD (67.23 \pm 12.60 years) } & $>67$ & $11(39.3)$ & $6(54.5)$ & $5(45.5)$ & 0.041 \\
\hline & $\leq 67$ & $17(60.7)$ & $3(17.6)$ & $14(82.4)$ & \\
\hline \multirow[t]{2}{*}{ Gender } & Male & $23(82.1)$ & $9(39.1)$ & $14(60.9)$ & 0.09 \\
\hline & Female & $5(17.9)$ & 0 & $5(100)$ & \\
\hline \multirow[t]{3}{*}{ Histological grade } & Well & $13(46.4$ & $2(15.4)$ & $11(84.6)$ & 0.2 \\
\hline & Moderate & $11(39.3)$ & $5(45.5)$ & $6(54.5)$ & \\
\hline & Poor & $4(14.3)$ & $2(50)$ & $2(50)$ & \\
\hline \multirow[t]{3}{*}{ Tumor size } & $\leq 4 \mathrm{~mm}$ & $4(14.3)$ & $2(50)$ & $2(50)$ & 0.1 \\
\hline & $>4 \mathrm{~mm}$ & $4(14.3)$ & $0(0)$ & $4(100)$ & \\
\hline & No data & $20(71.4)$ & $7(35)$ & $13(65)$ & \\
\hline \multirow[t]{2}{*}{ Ulceration } & Yes & $2(7.1)$ & 0 & $2(100)$ & 0.31 \\
\hline & No & $26(92.8)$ & $9(34.6)$ & $17(65.5)$ & \\
\hline \multirow[t]{2}{*}{ Tumor-infiltrating lymphocytes } & Yes & $1(3.6)$ & $1(100)$ & 0 & 0.13 \\
\hline & No & $27(96.4)$ & $8(29.6)$ & $19(70.4)$ & \\
\hline \multirow[t]{2}{*}{ Perineural invasion (PNI) } & Yes & $1(3.6)$ & 0 & $1(100)$ & 0.48 \\
\hline & No & $27(96.4)$ & $9(33.3)$ & $18(66.7)$ & \\
\hline \multirow[t]{3}{*}{ Invasive and in situ forms } & Invasive & $12(42.8)$ & $7(58.3)$ & $5(41.7)$ & 0.25 \\
\hline & In situ & $2(7.14)$ & $2(100)$ & 0 & \\
\hline & No data & $14(50)$ & 0 & $14(100)$ & \\
\hline \multirow[t]{2}{*}{ Margin involvement } & Yes & $2(7.1)$ & 0 & $2(100)$ & 0.31 \\
\hline & No & $26(92.8)$ & $9(34.6)$ & $17(65.4)$ & \\
\hline
\end{tabular}

nodular BCC, which are two main histological types of BCC. Since the numbers are small and, therefore, would not support a chi-squared test for trend on a contingency with missing data. However, Fisher's exact test also was not significant for this analysis $(P>0.99)$. We also could not find any positive trend between lentigo and superficial spreading melanoma both in statistical analysis, and pathological review. Also, it was the same for BCC superficial versus nodular.

\section{Discussion}

In this study, we found LINE-1 ORF1p ORF1p immunoreactivity in various skin tumor subtypes that are in line with previous studies of LINE-1 expression in different cancers. As previously reported [32], ORF1p is expressed 200-fold than ORF2p, so tracking ORF1p throughout disease progression can provide valuable insights regarding retrotransposition events or the impact of LINE-1 expression on the genome.

Overall, LINE-1 ORF1p overexpression can be used as a specific hallmark for diagnosing human malignancies [17]. In the vast majority tumors including approximately $90 \%$ of breast, ovarian, pancreatic cancers, more than half of tubular gastrointestinal tract cancers comprising esophageal and colon cancers and also $50 \%$ of lung cancers and $40 \%$ of prostate tumors, ORF1p can be detected by immunohistochemistry [14, 17]. As mentioned, LINE-1 activation/expression is associated with genomic instability that is a hallmark and characteristics in malignant tumors, including melanoma. Because of this, we expected to get a wide range of LINE-1 expression in MM patients. In the current study, we found significant expression of ORF1p in BCC samples in comparison to SCC and melanoma. ORF1p immunolabeling in $\mathrm{BCC}$ samples was higher than those of melanoma samples in contrary to our hypothesis. The reason why the ORF1p expression in NMSC was higher than malignant melanoma requires more attention.

Carcinogenesis in skin tissues is associated with exposure to different environmental factors. Previous reports have shown that some environmental factors like gamma irradiation and $\mathrm{X}$ - rays some environmental agents such as benzo [a] pyrene $(\mathrm{B}[\mathrm{a}] \mathrm{P})$, organochlorine pesticides, food-borne carcinogens, extremely low-frequency magnetic fields (ELF-MF) and some heavy metals like arsenic, aluminum increase L1 retrotransposition events [33-35]. Since the skin is the first line of defense for mentioned factors, so the higher expression of the level of ORF1 due to the exposure to agents is plausible. 
Table 3 Association of LINE-1ORF1p expression with clinicopathological parameters in MM

\begin{tabular}{|c|c|c|c|c|c|}
\hline Clinicopathological characteristics & & $\begin{array}{l}\text { Total } \\
\text { Number } \\
(\%)\end{array}$ & \multicolumn{2}{|c|}{ ORF1P expression (mean $\boldsymbol{H}$-score $=46.27$ ) } & $\begin{array}{l}\boldsymbol{P} \\
\text { value }\end{array}$ \\
\hline \multirow[t]{2}{*}{ Mean age $\pm S D$ (65.1 \pm 14.2 years) } & $>65$ & $15(48.4)$ & $5(33.3)$ & $10(66.7)$ & 0.60 \\
\hline & $\leq 65$ & $16(51.6)$ & $4(25)$ & $12(75)$ & \\
\hline \multirow[t]{2}{*}{ Gender } & Male & $18(58.1)$ & $6(33.3)$ & $12(66.7)$ & 0.53 \\
\hline & Female & $13(41.9)$ & $3(23.1)$ & $10(76.9)$ & \\
\hline \multirow[t]{3}{*}{ Ulceration } & Yes & $6(19.4)$ & 0 & $6(100)$ & 0.07 \\
\hline & No & $18(58.1)$ & $7(38.9)$ & $11(61.1)$ & \\
\hline & No data & $7(22.6)$ & $2(28.6)$ & $5(71.4)$ & \\
\hline \multirow[t]{3}{*}{ Perineural invasion (PNI) } & Yes & $3(9.7)$ & 0 & $3(100)$ & 0.21 \\
\hline & No & $20(64.5)$ & $7(35)$ & $13(65)$ & \\
\hline & No data & $8(25.8)$ & $2(25)$ & $6(75)$ & \\
\hline \multirow[t]{3}{*}{ Metastasis } & Yes & $12(38.7)$ & $6(50)$ & $6(50)$ & 0.26 \\
\hline & No & $8(25.8)$ & $2(25)$ & $6(75)$ & \\
\hline & No data & $11(35.5)$ & $1(9.1)$ & $10(90.9)$ & \\
\hline \multirow[t]{3}{*}{ Local recurrence } & Yes & $17(54.8)$ & $7(41.2)$ & $10(58.8)$ & 0.16 \\
\hline & No & $3(9.7)$ & 0 & $3(100)$ & \\
\hline & No data & $11(35.5)$ & $2(18.2)$ & $9(81.8)$ & \\
\hline \multirow[t]{3}{*}{ Tumor-infiltrating lymphocytes } & Yes & $6(19.4)$ & 0 & $6(100)$ & 0.19 \\
\hline & No & $4(12.9)$ & $1(25)$ & $3(75)$ & \\
\hline & No data & $21(67.7)$ & $8(38.1)$ & $13(61.9)$ & \\
\hline \multirow[t]{3}{*}{ Lymphovascular invasion } & Yes & $7(22.6)$ & $1(14.3)$ & $6(85.7)$ & 0.79 \\
\hline & No & $5(16.1)$ & $1(20)$ & $4(80)$ & \\
\hline & No data & $19(61.3)$ & $7(36.8)$ & $12(63.2)$ & \\
\hline \multirow[t]{3}{*}{ Margin involvement } & Yes & $7(23.3)$ & $2(28.6)$ & $5(71.4)$ & 0.5 \\
\hline & No & $18(60)$ & $3(16.7)$ & $15(83.3)$ & \\
\hline & No data & $6(16.7)$ & $4(66.7)$ & $2(33.3)$ & \\
\hline \multirow[t]{3}{*}{ Breslow thickness } & Thin $(\leq 1 \mathrm{~mm})$ & $2(6.5)$ & 0 & $2(100)$ & 0.59 \\
\hline & Thick (> 1 mm) & $8(25.8)$ & $1(12.5)$ & $7(87.5)$ & \\
\hline & No data & $21(67.7)$ & $8(38.1)$ & $13(61.9)$ & \\
\hline \multirow[t]{3}{*}{ Clark level } & Group $1(\mathrm{I}, \mathrm{II})$ & 7 (22.6) & $1(14.3)$ & $6(85.7)$ & 0.33 \\
\hline & Group 2 (III-V) & $6(19.4)$ & 0 & $6(100)$ & \\
\hline & No data & $18(58.1)$ & $8(44.4)$ & $10(55.6)$ & \\
\hline
\end{tabular}

Melanoma tumors have higher levels of genomic instability [9] and are associated with hypomethylation of genomic LINE-1 sequences [23, 36]. However, we expected to get more expression level of ORF1p in melanoma, what caused to observe such a decreased level in comparison to other subtypes remains a mystery for us. Likely, the monoclonal LINE-1 ORF1p antibody referenced in this study that recognizes the sequence corresponding to amino acids 35 to 44 of LINE-1 ORF1p (MENDFDELRE) has not the capability for targeting those sequences in melanoma. It seems that conventional antigen retrieval pathways are not sufficient for retrieving LINE1 ORF1p immunolabelling. In SCC cases, a trend towards increasing the correlation of ORF1p expression with age was observed, which supports the evidence that age can play a role in developing SCC.

We observed both cytoplasmic and nuclear pattern of LINE-1ORF1p expression in all of the samples, while the cytoplasmic pattern has been predominantly represented in some cancers [17]. In breast cancers, local relapse, as well as distal metastases and poorer overall survival with tumors displaying nuclear L1-ORF1p in contrast to cytoplasmic L1-ORF1p group, have been observed [37]. Distinguishing and quantification between cytoplasmic and nuclear expression can be highlighted in skin tumor subtypes in future studies. 


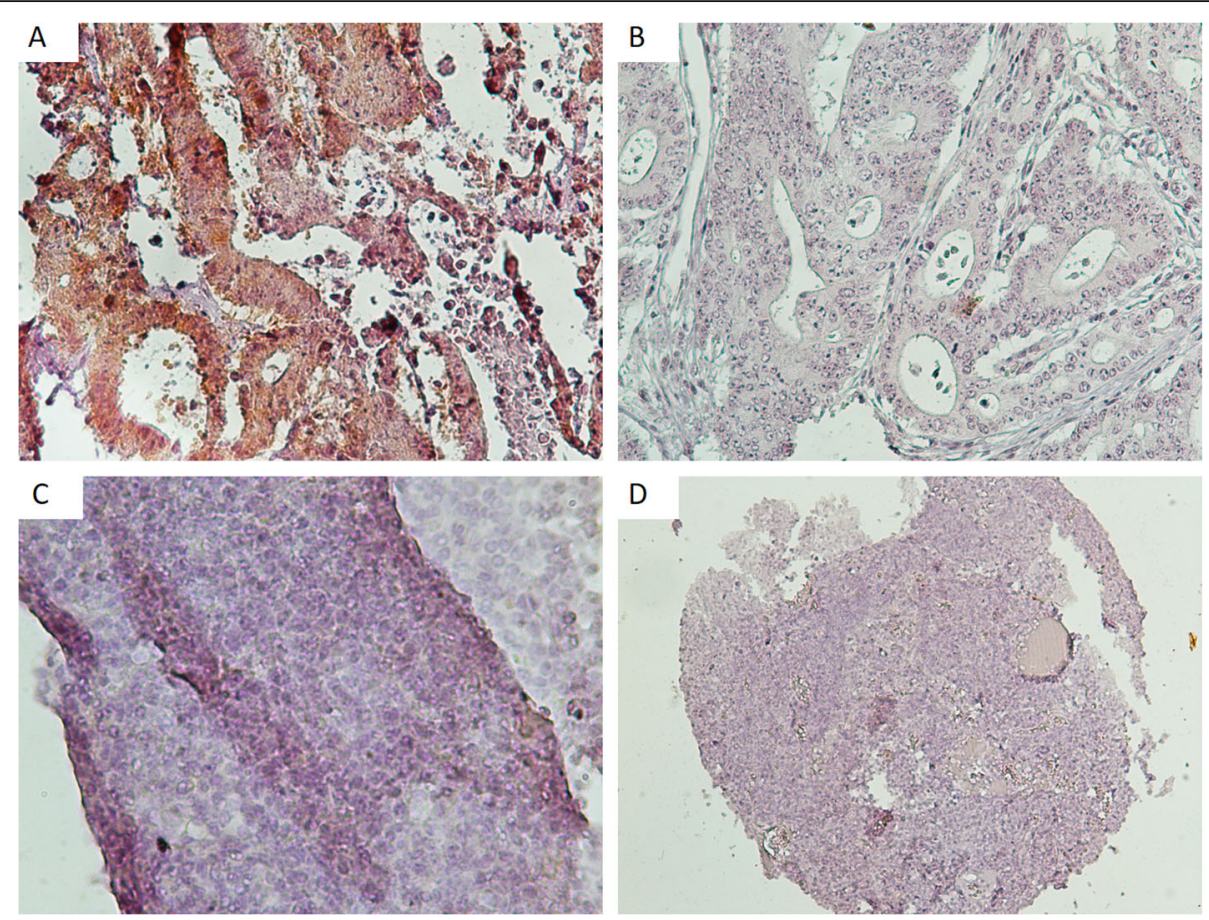

Fig. $1 \mathrm{HC}$ staining of colorectal, surgical intestinal resection margins in colon cancer, and normal skin tissues. a Positive immunoreactive LINE-1 ORF1p in CRC, $\mathbf{b}$ negative surgical resection margin sample for LINE-1 ORF1p, $\mathbf{c}$ and $\mathbf{d}$ are representative for normal skin tissues with different magnifications
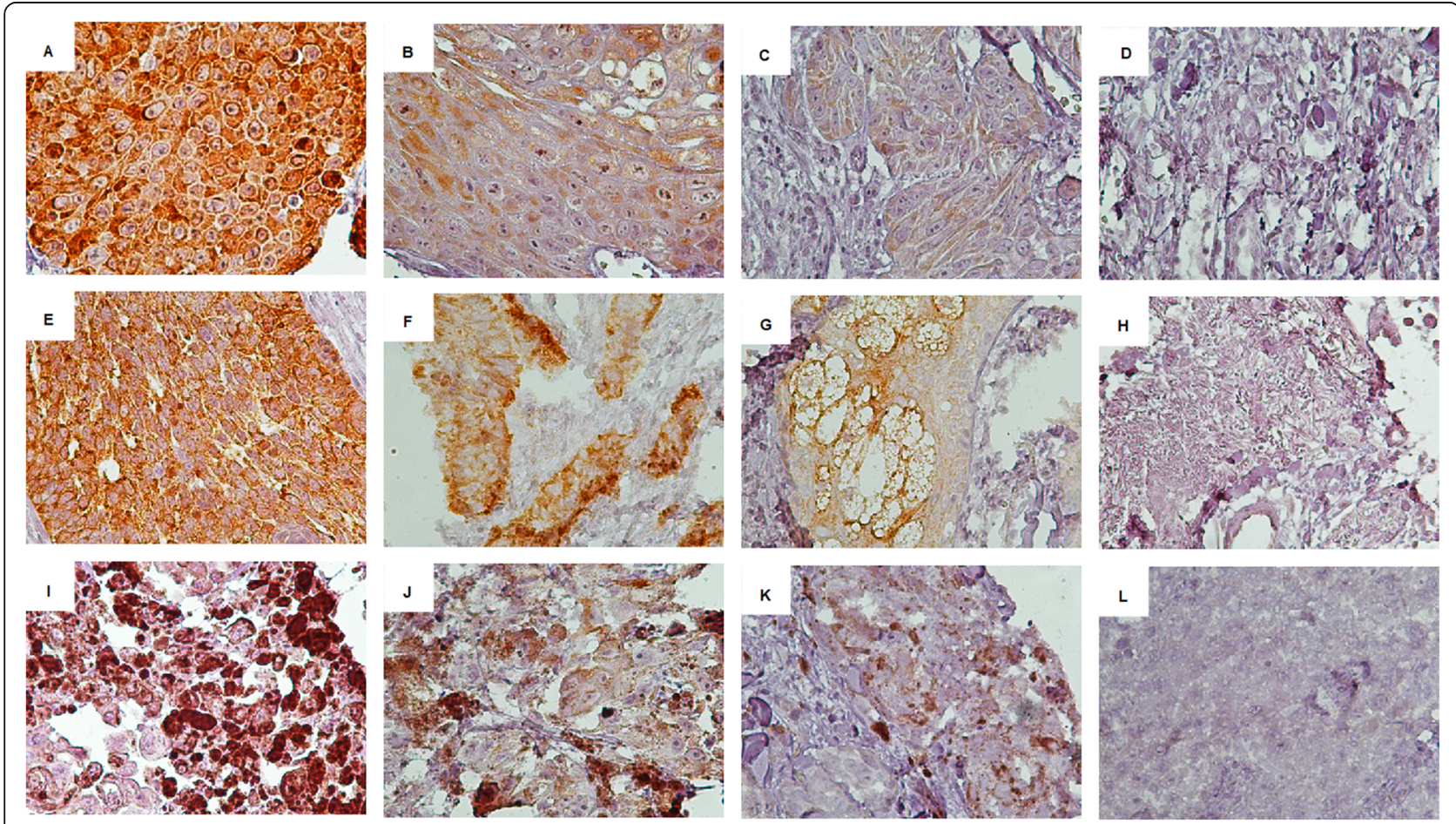

Fig. 2 Immunohistochemical analysis of LINE-1ORF1p expression in different skin cancer subtypes. LINE-1 ORF1p expression in SCC: a + 3, strong; $\mathbf{b}+2$, moderate; $\mathbf{c}+1$, weak; $\mathbf{d}$ 0, no intensity. LINE-1ORF1p expression in BCC: $\mathbf{e}+3$, strong; $\mathbf{f}+2$, moderate; $\mathbf{g}+1$, weak; $\mathbf{h} 0$, no intensity. LINE1ORF1p expression in melanoma: $\mathbf{i}+3$, strong; $\mathbf{j}+2$, moderate; $\mathbf{k}+1$, weak; $\mathbf{I} 0$, no intensity 


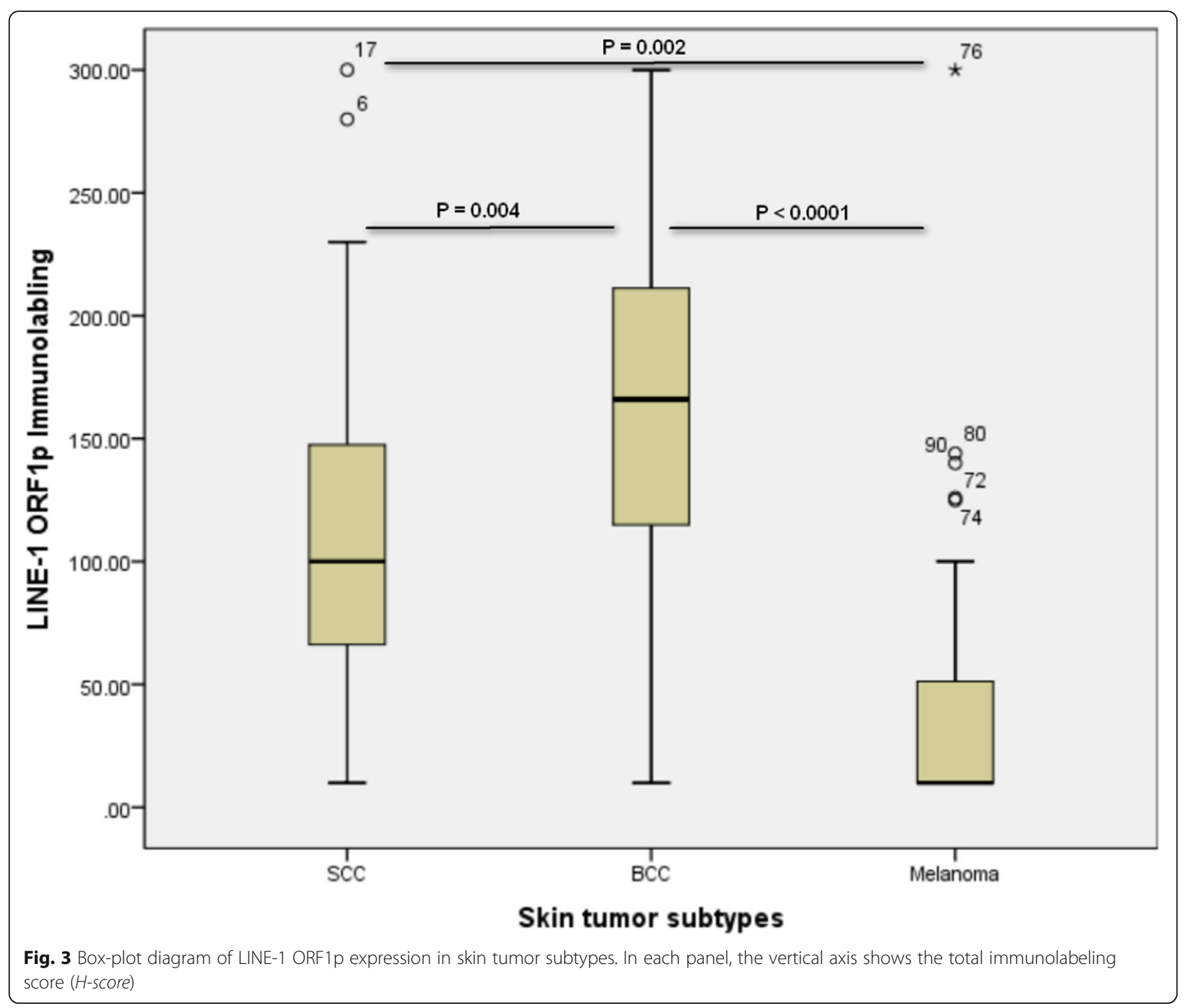

Each genome harbors different copies of 80-100 potentially active L1 elements, and this partly explains the variability in somatic insertions of L1 elements within tumors [38]. How many full length - potentially active elements contribute to immunoreactivity for LINE-1 ORF1p and whether observed heterogeneity in these subsets of skin tumor subtypes is related to differences in the inherited complement of active L1 elements or not remains to be robustly evaluated. Evaluating such heterogeneity in melanoma cases may pave finding the reason for such differences. Since the tumor microenvironment is a key contributor in cutaneous malignancies progression, studying L1 hypomethylation of functional L1 promoters and their genomic sequences in precancerous lesions can offer a genuine reservoir for finding novel targets for both therapeutic purposes and risk assessments in skin cancers.
In this context and according to our findings, clinical information on the potential utility of LINE-1 ORF1p expression and activation as a novel biomarker in skin neoplasms are, however, limited, and future investigations should be directed towards identifying a correlation between LINE-1 expression and histopathological or diagnostic implication for practitioners is needed. If the value of ORF1p expression is clinically validated in SCC and BCC patients, such information will help clinicians make better decisions for prognosis and plan treatment and follow-up of patients.

\section{Conclusions}

Evidence from basic and translational science indicates a correlation between LINE-1 induction and tumorigenesis, cancer progression, and therapeutic response. Despite ample evidence, the causal and mechanistic links between LINE-1ORF1p expression and the development 
of different cancers are still unraveled. According to our observation, LINE-1 ORF1p immunoreactivity in various skin tumor subtypes confirms previous studies of LINE1 expression in different cancers. LINE-1 ORF1p overexpression in NMSCs compared with MM can be considered with caution as a tumor-specific antigen for NMSCs.

\section{Abbreviations}

NMSCs: Nonmelanoma skin cancers; LINE-1, L1: Long Interspersed Element-1. ORF1p: Open reading frame 1 protein; MM: Malignant melanoma; BCC: Basal cell carcinoma; SCC: Squamous cell carcinoma; TMA: Tissue microarray; $\mathrm{H}$ score: Histochemical score; UVR: Ultraviolet radiation; TEs: Transposable Elements; UTR: Untranslated region; ORF: Open reading frame; FFPE: Formalin-fixed paraffin-embedded; TILs: Tumor-infiltrating lymphocytes; PNI: Perineural invasion; IHC: Immunohistochemistry

\section{Acknowledgments}

We are thankful to the staff of the Oncopathology Research Center, Iran University of Medical Sciences, Tehran, Iran.

\section{Authors' contributions}

All authors have read and approved the manuscript. MAZ, EK, ARK, ARG, AK performed the research. AK and ZM designed the research study. ZM, NE, AN-ER, KK contributed essential reagents or tools. AK analyzed the data. MAZ and AK wrote the paper.

\section{Funding}

This research was supported by Deputy of Research and Technology, Tehran University of Medical Sciences, Tehran, Iran, Grant/Award Number: 94-03-3029952. The funding source had no involvement in study design, collection, analysis, and interpretation of data, writing of the report, and in the decision to submit the article for publication.

\section{Availability of data and materials}

The data that support the findings of this study are available from the corresponding author, $[\mathrm{AK}]$, upon reasonable request.

\section{Ethics approval and consent to participate}

The present study was performed in accordance with the 1975 Declaration of Helsinki. Informed consent was obtained from all individual participants included in the study. All experiments are approved by the Tehran University of Medical Sciences Research Ethics Committee in Iran (Ref no: IR.TUMS.REC.1394.1570).

\section{Consent for publication}

Not applicable.

\section{Competing interests}

The authors declare that there are no conflicts of interest to disclose regarding funding from industrial sources or other disclosures concerning this manuscript.

\footnotetext{
Author details

'Department of Molecular Medicine, Faculty of Advanced Medical Sciences, Tabriz University of Medical Sciences, Tabriz, Iran. ${ }^{2}$ Department of Dermatology, Razi Hospital, Tehran University of Medical Sciences, Tehran, Iran. ${ }^{3}$ Oncopathology Research Center, Iran University of Medical Sciences, Tehran, Iran. ${ }^{4}$ Department of Dermatopathology, Razi Dermatology Hospital, Tehran University of Medical Sciences, Tehran, Iran. ${ }^{5}$ Autoimmune Bullous Diseases Research Center, Tehran University of Medical Sciences, Tehran, Iran. ${ }^{6}$ Iran National Tumor Bank, Cancer Institute, Tehran University of Medical Sciences, Tehran, Iran.
}

Received: 3 August 2019 Accepted: 8 June 2020

Published online: 17 June 2020

\section{References}

1. Gordon R. Skin cancer: an overview of epidemiology and risk factors. Semin Oncol Nurs. 2013;29(3):160-9.

2. Fahradyan A, Howell AC, Wolfswinkel EM, Tsuha M, Sheth P, Wong AK. Updates on the Management of Non-Melanoma Skin Cancer (NMSC). Healthcare (Basel, Switzerland). 2017:5(4):82.

3. Apalla Z, Lallas A, Sotiriou E, Lazaridou E, loannides D. Epidemiological trends in skin cancer. Dermatol Pract Concept. 2017:7(2):1-6.

4. Cummins DL, Cummins JM, Pantle H, Silverman MA, Leonard AL, Chanmugam A. Cutaneous malignant melanoma. Mayo Clin Proc. 2006; 81(4):500-7

5. Nerad JA. All skin cancers are not created equal. Br J Ophthalmol. 2007; 91(3):276-7.

6. Rigel DS, Russak J, Friedman R. The evolution of melanoma diagnosis: 25 years beyond the ABCDs. CA Cancer J Clin. 2010;60(5):301-16.

7. Netscher DT, Leong M, Orengo I, Yang D, Berg C, Krishnan B. Cutaneous malignancies: melanoma and non-melanoma types. Plast Reconstr Surg. 2011;127(3):37e-56e

8. Fabbrocini G, Triassi M, Mauriello MC, Torre G, Annunziata MC, De Vita V, Pastore F, D'Arco V, Monfrecola G. Epidemiology of skin cancer: role of some environmental factors. Cancers. 2010:2(4):1980-9.

9. Kaufmann WK, Carson CC, Omolo B, Filgo AJ, Sambade MJ, Simpson DA, Shields JM, Ibrahim JG, Thomas NE. Mechanisms of chromosomal instability in melanoma. Environ Mol Mutagen. 2014;55(6):457-71.

10. Cordaux R, Batzer MA. The impact of retrotransposons on human genome evolution. Nat Rev Genet. 2009;10(10):691-703.

11. Lander ES, Linton LM, Birren B, Nusbaum C, Zody MC, Baldwin J, Devon K, Dewar K, Doyle M, FitzHugh W, et al. Initial sequencing and analysis of the human genome. Nature. 2001;409(6822):860-921.

12. Chen L, Dahlstrom JE, Chandra A, Board P, Rangasamy D. Prognostic value of LINE-1 retrotransposon expression and its subcellular localization in breast cancer. Breast Cancer Res Treat. 2012;136(1):129-42.

13. Sokolowski M, Chynces M, deHaro D, Christian CM, Belancio VP. Truncated ORF1 proteins can suppress LINE-1 retrotransposition in trans. Nucleic Acids Res. 2017:45(9):5294-308.

14. Ardeljan D, Taylor MS, Ting DT, Burns KH. The human long interspersed Element-1 Retrotransposon: an emerging biomarker of Neoplasia. Clin Chem. 2017:63(4):816-22

15. Gong J, Zhang Q, Wang Q, Ma Y, Du J, Zhang Y, Zhao X. Identification and verification of potential piRNAs from domesticated yak testis. Reproduction (Cambridge, England). 2018;155(2):117-27.

16. Kerachian MA, Kerachian M. Long interspersed nucleotide element-1 (LINE1) methylation in colorectal cancer. Clin Chim Acta. 2019;488:209-14.

17. Rodic N, Sharma R, Sharma R, Zampella J, Dai L, Taylor MS, Hruban RH, lacobuzio-Donahue CA, Maitra A, Torbenson MS, et al. Long interspersed element-1 protein expression is a hallmark of many human cancers. Am J Pathol. 2014;184(5):1280-6.

18. Daskalos A, Nikolaidis G, Xinarianos G, Savvari P, Cassidy A, Zakopoulou R, Kotsinas A, Gorgoulis V, Field JK, Liloglou T. Hypomethylation of retrotransposable elements correlates with genomic instability in non-small cell lung cancer. Int J Cancer. 2009;124(1):81-7.

19. Saito K, Kawakami K, Matsumoto I, Oda M, Watanabe G, Minamoto T. Long interspersed nuclear element 1 hypomethylation is a marker of poor prognosis in stage IA non-small cell lung cancer. Clin Cancer Res. 2010;16(8): 2418-26.

20. Sunami E, de Maat M, Vu A, Turner RR, Hoon DS. LINE-1 hypomethylation during primary colon cancer progression. PLoS One. 2011;6(4):e18884.

21. van Hoesel $A Q$, van de Velde CJ, Kuppen PJ, Liefers GJ, Putter H, Sato Y, Elashoff DA, Turner RR, Shamonki JM, de Kruijf EM, et al. Hypomethylation of LINE-1 in primary tumor has poor prognosis in young breast cancer patients: a retrospective cohort study. Breast Cancer Res Treat. 2012;134(3): 1103-14.

22. Park SY, Seo AN, Jung HY, Gwak JM, Jung N, Cho NY, Kang GH. Alu and LINE-1 hypomethylation is associated with HER2 enriched subtype of breast cancer. PLoS One. 2014;9(6):e100429.

23. Pramio DT, Pennacchi PC, Maria-Engler SS, Campos AH, Duprat JP, Carraro DM, Krepischi AC. LINE-1 hypomethylation and mutational status in cutaneous melanomas. J Investig Med. 2016;64(4):899-904. 
24. Taylor MS, LaCava J, Mita P, Molloy KR, Huang CR, Li D, Adney EM, Jiang H, Burns $\mathrm{KH}$, Chait BT, et al. Affinity proteomics reveals human host factors implicated in discrete stages of LINE-1 retrotransposition. Cell. 2013;155(5):1034-48.

25. Kabbarah O, Nogueira C, Feng B, Nazarian RM, Bosenberg M, Wu M, Scott KL, Kwong LN, Xiao Y, Cordon-Cardo C, et al. Integrative genome comparison of primary and metastatic melanomas. PLoS One. 2010;5(5):e10770.

26. Kabbarah O, Chin L. Revealing the genomic heterogeneity of melanoma. Cancer Cell. 2005;8(6):439-41.

27. Kononen J, Bubendorf L, Kallioniemi A, Barlund M, Schraml P, Leighton S, Torhorst J, Mihatsch MJ, Sauter G, Kallioniemi OP. Tissue microarrays for high-throughput molecular profiling of tumor specimens. Nat Med. 1998; 4(7):844-7.

28. Ronald Simon MM. And Guido Sauter: tissue microarrays. BioTechniques. 2004;36:98-105.

29. Sabet MN, Rakhshan A, Erfani E, Madjd Z. Co-expression of putative cancer stem cell markers, CD133 and nestin, in skin tumors. Asian Pac J Cancer Prev. 2014;15(19):8161-9.

30. Erfani E, Roudi R, Rakhshan A, Sabet MN, Shariftabrizi A, Madjd Z. Comparative expression analysis of putative cancer stem cell markers CD44 and ALDH1A1 in various skin cancer subtypes. Int J Biol Markers. 2016;31(1):e53-61.

31. Balch CM, Gershenwald JE, Soong SJ, Thompson JF, Atkins MB, Byrd DR, Buzaid AC, Cochran AJ, Coit DG, Ding S, et al. Final version of 2009 AJCC melanoma staging and classification. J Clin Oncol. 2009;27(36):6199-206.

32. Martin SL. Nucleic acid chaperone properties of ORF1p from the non-LTR retrotransposon, LINE-1. RNA Biol. 2010;7(6):706-11.

33. Karimi A, Madjd Z, Habibi L, Akrami SM. Exposure of hepatocellular carcinoma cells to low-level as (2) O (3) causes an extra toxicity pathway via L1 retrotransposition induction. Toxicol Lett. 2014;229(1):111-7.

34. Karimi A, Madjd Z, Habibi L, Akrami SM. Evaluating the extent of LINE-1 mobility following exposure to heavy metals in HepG2 cells. Biol Trace Elem Res. 2014;160(1):143-51.

35. Del Re B, Marcantonio P, Gavoci E, Bersani F, Giorgi G. Assessing LINE-1 retrotransposition activity in neuroblastoma cells exposed to extremely lowfrequency pulsed magnetic fields. Mutat Res. 2012;749(1-2):76-81.

36. Hoshimoto S, Kuo CT, Chong KK, Takeshima TL, Takei Y, Li MW, Huang SK, Sim MS, Morton DL, Hoon DS. AIM1 and LINE-1 epigenetic aberrations in tumor and serum relate to melanoma progression and disease outcome. $J$ Investig Dermatol. 2012;132(6):1689-97.

37. Harris CR, Normart R, Yang Q, Stevenson E, Haffty BG, Ganesan S, CordonCardo C, Levine AJ, Tang LH. Association of nuclear localization of a long interspersed nuclear element-1 protein in breast tumors with poor prognostic outcomes. Genes Cancer. 2010;1(2):115-24.

38. Doucet-O'Hare TT, Rodic N, Sharma R, Darbari I, Abril G, Choi JA, Young Ahn J, Cheng Y, Anders RA, Burns KH, et al. LINE-1 expression and retrotransposition in Barrett's esophagus and esophageal carcinoma. Proc Natl Acad Sci U S A. 2015;112(35):E4894-900

\section{Publisher's Note}

Springer Nature remains neutral with regard to jurisdictional claims in published maps and institutional affiliations.

Ready to submit your research? Choose BMC and benefit from:

- fast, convenient online submission

- thorough peer review by experienced researchers in your field

- rapid publication on acceptance

- support for research data, including large and complex data types

- gold Open Access which fosters wider collaboration and increased citations

- maximum visibility for your research: over $100 \mathrm{M}$ website views per year

At $\mathrm{BMC}$, research is always in progress.

Learn more biomedcentral.com/submissions 